\title{
Elucidation of the role of breathless, a Drosophila FGF receptor homolog, in tracheal cell migration
}

\author{
Michal Reichman-Fried, Barry Dickson, ${ }^{1}$ Ernst Hafen, ${ }^{1}$ and Ben-Zion Shilo ${ }^{2}$ \\ Department of Molecular Genetics and Virology, Weizmann Institute of Science, Rehovot 76100, Israel; ${ }^{1}$ Zoologisches \\ Institut der Universität Zürich, CH-8057, Zürich, Switzerland
}

\begin{abstract}
DFGF-R1 (breathless), a Drosophila FGF receptor homolog, is required for the migration of tracheal cells and the posterior midline glial cells during embryonic development. To define the role of this receptor in cell migration, we have monitored the biological effects of a deregulated receptor containing the extracellular and transmembrane regions of the torso dominant allele and the cytoplasmic domain of DFGF-R1. Ubiquitous expression of the chimeric receptor at the time of tracheal cell migration did not disrupt migration in wild-type embryos. However, induction of the chimeric receptor corrected the tracheal defects of breathless (btI) mutant embryos, allowing the tracheal cells to migrate along their normal tracts. This result indicates that the normal activity of DFGF-R1 in promoting cell migration does not require spatially restricted cues. Late inductions of the chimeric construct, after the normal initiation of tracheal migration, allowed the definition of a broad time window during which the external signals guiding migration persist and the tracheal cells retain the capacity to respond to these cues. Rescue of tracheal migration in btl mutant embryos by the chimeric construct provides a sensitive biological assay for the activity of other Drosophila receptor tyrosine kinases (RTKs). Deregulated receptors containing the cytoplasmic domains of DFGF-R2, DER, torso, and sevenless were all able to partially rescue the migration defects. Consistent with the notion that these RTKs share a common signaling pathway, constructs containing the activated downstream elements Dras1 and Draf were also able to rescue tracheal migration, demonstrating that these two proteins are key players in the DFGF-R1 signaling pathway.
\end{abstract}

[Key Words: Receptor tyrosine kinase; Drosophila; tracheal development; cell migration; FGF; ras; raf]

Received October 18, 1993; accepted in revised form December 20, 1994.

Elaborate processes of cell migration constitute the formation of structures with highly stereotyped patterns during development. Such precise patterning establishes the basis for the proper functioning of tissues that reach and connect to different parts of the developing embryo, like cells and axons of the nervous system, muscle cells, and endothelial cells forming blood vessels and the tracheal system. Underlying migration of cells along specific pathways are mechanisms of path finding and target recognition, which are facilitated by the responses to lo$\mathrm{cal}$ and distant external signals. Local signals that dictate the direction of growth can be mediated by molecules such as membrane-associated proteins anchored to the surface of cells encountered by migrating cells, molecules associated with the extracellular matrix that surrounds the route of migration, and diffusible factors (reviewed for the nervous system by Goodman and Shatz 1993). To respond to these guiding cues, migrating cells must express the corresponding surface receptors that would induce the required intracellular changes upon

${ }^{2}$ Corresponding author. activation. Putative ligand-receptor interactions that are involved in the process of path finding have been exemplified in studies of Caenorhabditis elegans: unc-5 and unc-6 genes are required for guiding pioneer neurons along the body wall. Unc- 5 is a transmembrane protein expressed on motile cells and growth cones, whereas Unc-6 is a laminin-related glycoprotein and is proposed to be a component of the extracellular matrix and a ligand of Unc-5 (Ishii et al. 1992; Leung-Hagesteijn et al. 1992). In support of the directive role played by Unc-5 and Unc- 6 in guiding migration, it has been recently demonstrated that ectopic expression of Unc- 5 results in reorientation of migrating growth cones, a process that depends on the presence of Unc-6 (Hamelin et al. 1993). However, for most of the processes involving guided cell migration, the molecules dictating directionality have not been identified.

A model system that can serve to unravel the mechanisms and molecules that drive and guide cell migration is the tracheal system of Drosophila. During early stages of embryonic development, several tracheal cell divisions occur giving rise to $\sim 90$ cells in each of the 10 
tracheal pits that are aligned on each side of the embryo. The process of cell migration is initiated only upon completion of tracheal cell division; about 1800 tracheal cells, stemming from the tracheal pits, migrate to form the tracheal branches that reach all tissues of the embryo while generating an intricate and characteristic network of tubes, referred to as the tracheal tree (Bier et al. 1989; Perrimon et al. 1991; Hartenstein and Jan 1992; Manning and Krasnow 1993).

A gene that appears crucial for tracheal-cell migration encodes the Drosophila homolog of fibroblast growth factor receptor (DFGF-R1) (Glazer and Shilo 1991; Klämbt et al. 1992). DFGF-R1 is a receptor tyrosine kinase (RTK) that contains the typical structural and functional domains of the FGF receptor family, including several immunoglobulin-like domains at the extracellular region and a split cytoplasmic kinase. It is evident from the phenotype of mutants that are defective at the DFGF-R1 locus that DFGF-R1 is essential for migration of tracheal cells. Tracheal-cell divisions and determination of general tracheal-cell fates appear to be unaffected by loss of the DFGF-R1 activity. However, these cells do not initiate migration and, consequently, do not generate the tracheal tree (Klämbt et al. 1992). On the basis of the failure of DFGF-R1 mutants to form the tracheal tree, the gene was termed breathless (btl). In btl mutants the migration of the posterior pair of the midline glial cells in each segment is also defective. These cells initiate their anterior migration, but fail to reach the posterior commissure of the next segment in mutant embryos (Klämbt et al. 1992). Given that DFGF-R1 expression in the embryo is restricted to the tracheal and midline cells, it is apparent that the biological effect of btl is manifested only in these tissues and thus its function is cell autonomous. Considering the migration defects in both tracheal and glial cells, it is clear that the DFGF-R1 protein is an essential component of migration processes that take place in different tissues of the developing embryo. However, the precise role of DFGF-R1 in these processes remains to be elucidated.

It is possible that DFGF-R1 plays a directive role during migration by responding to external guiding signals positioned along the migration tracts. Alternatively, DFGF-R1 may fulfill an essential requirement in the process of migration per se, for example, by affecting the cytoskeleton and the motility of migrating cells, influencing the interaction with the extracellular matrix or activating transcription of genes that are pivotal to various aspects of cell movement. To determine whether DFGF-R1 responds to spatially restricted signals, we set out to generate a constitutively activated DFGF-R1 protein and test its effect on tracheal-cell development in wild-type and btl mutant embryos. Toward this end, we constructed a chimeric receptor containing the extracellular domain of a constitutively activated torso RTK and the cytoplasmic kinase domain of DFGF-R1 (torsoDFGF-R1). A prototypic chimeric RTK of this kind has been described previously for the sevenless receptor (Dickson et al. 1992a). We postulated that if DFGF-R1 is involved in directing the routes of tracheal-cell migra- tion, the constitutively active chimeric protein should disrupt tracheal-cell migration in wild-type embryos. On the other hand, if DFGF-R1 plays a permissive role in the process of tracheal-cell migration, a rescue of tracheal phenotype of btl embryos should be expected.

Our results indicate that DFGF-R1 does not respond to spatially restricted cues because the arrest in tracheal migration of $b t l$ mutant embryos can be partially overcome on expression of the torso-DFGF-R1 chimera. Furthermore, torso chimeras containing the kinase domains of other Drosophila RTKs (DFGF-R2, DER, torso, and sevenless) can induce tracheal-cell migration in btl mutants albeit, to a lesser degree. Finally, activated Drasl and Draf proteins also corrected the migration defects. These results are consistent with a universal intracellular signaling cascade of RTKs. Notions concerning the possible contribution of DFGF-R1 to the process of migration are presented.

\section{Results}

Expression of the chimeric torso-DFGF-R1 receptor

To obtain a constitutively active DFGF-R1 protein we constructed a chimeric receptor in which the tyrosine kinase domain was derived from DFGF-R1, and the transmembrane and extracellular domains were contributed by the constitutively active torso protein (encoded by the torso ${ }^{4021}$ allele). The basis for constitutive activity of the mutant torso allele is the spontaneous dimerization of receptors due to a single amino acid substitution at the extracellular domain (Sprenger and NüssleinVolhard 1992; Dickson, Sprenger and Hafen, unpubl.). The torso-DFGF-R1 chimera was placed under the regulation of the inducible hsp70 promoter to allow temporally controlled and ubiquitous expression of the protein. Following insertion into a P-element vector, the construct was injected into embryos, and transformed lines, heterozygous for the chimeric construct, were obtained. Flies bearing an insertion of the construct into the second chromosome (strain ST4021R1.1) or the third chromosome (strain ST4021R1.2) were used in the following experiments.

To ascertain the synthesis of the torso-DFGF-R1 protein following heat shock and determine its turnover, 6-hr old embryos, progeny of heterozygous ST4021R1.1 flies, were heat shocked at $37^{\circ} \mathrm{C}$ for $20 \mathrm{~min}$ and transferred to $18^{\circ} \mathrm{C}$ for defined time periods. At each time point, a fixed number of embryos was lysed and fractionated by PAGE. The presence of the chimeric protein was examined by Western blot analysis utilizing antibodies specific for the cytoplasmic domain of DFGF-R1 (Glazer and Shilo 1991).

As seen in Figure 1, no torso-DFGF-Rl can be detected prior to heat shock. The endogenous DFGF-R1 protein is undetected in these blots as well, probably due to its expression only in a small fraction of embryonic cells and the limited sensitivity of the antibody. Following heat shock, the chimeric protein is detectable as a $\sim 150$ $\mathrm{kD}$ band $2 \mathrm{hr}$ after incubation at $18^{\circ} \mathrm{C}$ and is most prom- 


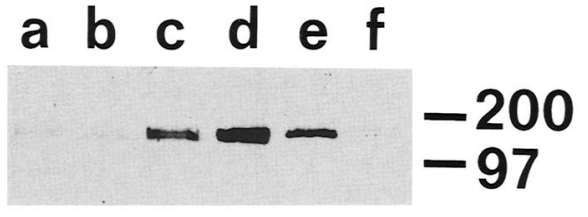

Figure 1. Kinetics of induction of the chimeric torso-DFGF-R1 protein in embryos. Embryos derived from a cross between flies heterozygous for the P[sE-torso ${ }^{4021}$-DFGF-R1] construct containing the torso-DFGF-Rl chimeric gene were aged to $6 \mathrm{hr}$ at $25^{\circ} \mathrm{C}$, heat shocked at $37^{\circ} \mathrm{C}$ and transferred to $18^{\circ} \mathrm{C}$. Extracts from $\geqslant 100$ embryos were prepared and the protein detected by overlaying the blots with antibodies directed against the cytoplasmic domain of DFGF-R1. Cell lysates were prepared at defined time points following heat shock and development at $18^{\circ} \mathrm{C}$. Samples represent $(a)$ no induction, or the following intervals at $18^{\circ} \mathrm{C}$ after induction: $(b) 30 \mathrm{~min} ;(c) 2 \mathrm{hr}_{;}(d) 4 \mathrm{hr} ;(e)$ $6 \mathrm{hr}$; and $(f) 8 \mathrm{hr}$. It should be noted that protein stain of the blot demonstrated that there was a comparable protein load in all the samples (not shown). Molecular weight markers are in kilodaltons.

inent at $4 \mathrm{hr}$. By $6 \mathrm{hr}$, the level of the protein declines, and at $8 \mathrm{hr}$ it is no longer detectable. Throughout the paper we will refer to the time of embryonic development at $25^{\circ} \mathrm{C}$ and not to the actual time that has elapsed at $18^{\circ} \mathrm{C}$. Accordingly, the chimeric protein appears $1 \mathrm{hr}$ after induction and disappears by $4 \mathrm{hr}$. Whole mount staining of ST4021R1.1 embryos with the same antibodies, following heat shock, confirmed the ubiquitous expression of the torso-DFGF-R1 chimera and the significant reduction in protein levels within $3 \mathrm{hr}$ (not shown).

The effect of torso-DFGF-R1 expression on tracheal migration in wild-type and btl embryos

Central to the elucidation of DFGF-R1 function is the question of whether constitutive activation of torsoDFGF-R1 chimera would disrupt normal tracheal migration. We reasoned that if DFGF-R1 responds to local external cues that delineate the route of migration, then its simultaneous activation in all tracheal cells should re- sult in the formation of an abnormal pattern of the tracheal tree. No deleterious effect on tracheal migration would imply that DFGF-R1 may normally be active in a spatially unrestricted manner, and therefore, constitutive activity of the torso-DFGF-R1 protein should rescue the tracheal phenotype of $b t l$ embryos.

To test the effect of the torso-DFGF-R1 chimera on tracheal cell migration in wild-type and mutant embryos, a genetic cross was designed to allow identification of the progeny of the relevant genotype (Fig. 2). One of the parental lines was heterozygous for both the torso-DFGF-R1 construct and the $b t 1^{H 82 \Delta 3}$ null allele. This $b t l$ allele has been generated by imprecise excision of the lacZ-containing P element inserted upstream of the DFGF-R1 locus. Homozygons $b t t^{H 82 \Delta 3}$ embryos show no DFGF-R1 expression, but retain $\beta$-gal expression in the tracheal and midline cells (Klämbt et al. 1992). The other parental line carries the null $b t l^{L G 19}$ allele generated by EMS mutagenesis (Klämbt et al. 1992), which is maintained over a marked third chromosome balancer expressing $\beta$-gal under the elav promoter. Thus, mutant embryos of the $b t l^{H 82 \Delta 3} / b t I^{L G 19}$ genotype generated in the cross could be identified on the basis of $\beta$-gal staining in the tracheal cells, contributed by the $b t l^{H 82 \Delta 3}$ allele, and the absence of balancer elav $\beta$-gal staining, indicating the presence of the $b t l^{L G 19}$ allele. Half of the progeny, whether wild type or mutant in $b t l$, carry the torso-DFGF-R1 construct on their second chromosome.

Staged embryos, generated in the cross, were heat shocked multiple times to allow for maximal expression of the activated torso-DFGF-R1 chimera during the wide time span of tracheal migration. Repeated heat shocks at 5 and $7 \mathrm{hr}$ of embryonic development were chosen as our first experimental protocol, because migration of tracheal cells initiates at stage 11 , that is, $5.5 \mathrm{hr}$ after egg lay (AEL), and all of the major branches are completed by stage 15 (13 hr AEL) (Manning and Krasnow 1993). Given that high levels of the chimeric protein are detectable for 2-3 hr following heat shock, this protocol should result in high levels of the chimeric protein throughout the stages of prominent tracheal migration. Because the
Figure 2. A scheme of the cross designed to test the effect of torso-DFGF-Rl on tracheal migration in wild-type and btl embryos. $b t 1^{H 82 \Delta 3}$ and $b t 1^{L G 19}$ represent two null $b t l$ alleles. tor-DFGF-R1 signifies the P-element-containing torso-DFGF-R1 chimeric construct and TM3 elav lacZ is a balancer chromosome marked by $\beta$-gal staining in the CNS. $b t t^{H 82 \Delta 3}$ shows $\beta$-gal expression in the tracheal cells, $b t l^{L G 19}$ does not show $\beta$-gal expression and TM3 elav lacZ shows $\beta$-gal expression in the CNS. Thus, staining with anti- $\beta$ gal antibodies allowed the identification of the homozygous btl mutant embryos.

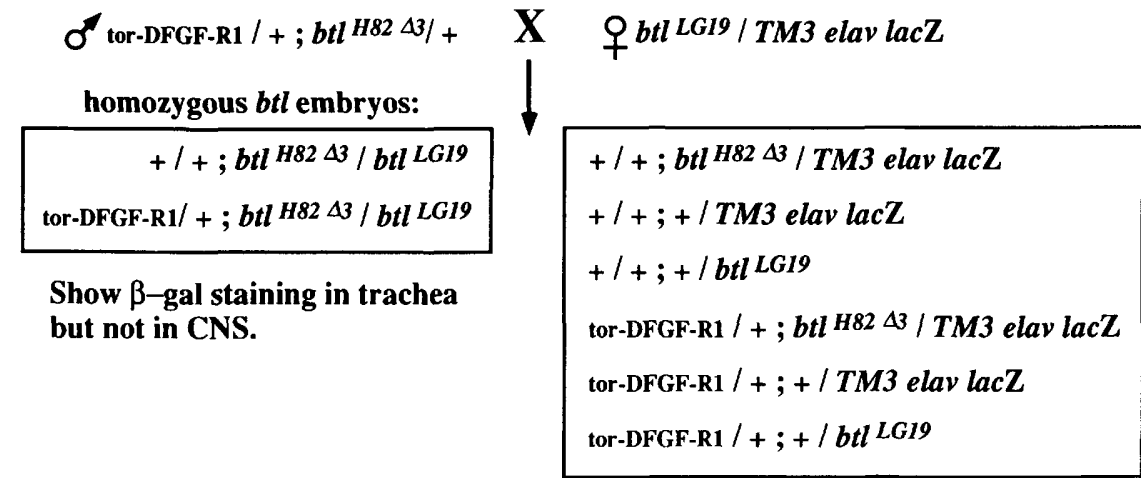

Show $\beta$-gal staining in CNS and trachea, staining only in CNS, or no staining. 
torso gain-of-function allele is more active at $18^{\circ} \mathrm{C}$ (Szabad et al. 1989), the heat-shocked embryos were transferred to $18^{\circ} \mathrm{C}$ for further development. The embryos were fixed at $11.5 \mathrm{hr}$ and then stained with antibody 55 that labels the lumen of the tracheal tubes (L. Glazer and B.-Z. Shilo, unpubl.) and with anti- $\beta$-gal antibodies that served to identify the genotype of the embryos.

About 3/4 of the progeny exhibited a normal tracheal morphology, as demonstrated by antibody 55 staining and exemplified in Figure 3A. These embryos contained only one or no mutant $b t$ lalleles, as established by $\beta$-gal staining. Half of them should carry the chimeric construct. About one-eighth of the embryos showed the typical btl null tracheal phenotype (Fig. 3B). As indicated by $\beta$-gal staining, those are the embryos of the $b t 1^{H 82 \Delta 3}$ / $b t l^{L G 19}$ genotype that presumably do not contain the chimeric construct (Fig. 3C). Remarkably, however, the remaining $\sim 1 / 8$ of the embryos that were of the $b t l^{H 82 \Delta 3} / b t l^{L G 19}$ genotype as well (as established by $\beta$-gal staining, Fig. 3e), showed a significant rescue of the null $b t l$ phenotype (Fig. 3d,e). A continuous dorsal trunk was formed in most anterior and posterior segments. The lateral branches migrating toward the ventral ectoderm were substantially elongated, and the visceral branches reached half of their normal length (i.e., approximately one segment across). All the migrating tracheal branches appear to follow the normal routes of outgrowth. Similar results were obtained in $b t l^{L G 19}$ homozygous embryos containing an independent insertion of the torso-DFGFR1 construct on the third chromosome (Fig. 3f). It should be noted that multiple heat shocks of embryos heterozygous or homozygous for btl whose parental lines lacked the chimeric construct, resulted in formation of the characteristic wild-type or $b t l$ tracheal phenotype, respectively. The rescued $b t l$ phenotype was not observed in these experiments (not shown). It is therefore the presence of the constitutively active torso-DFGF-R1 protein that has brought about the partial rescue of tracheal migration in the homozygous btl embryos.

The hallmarks of the rescued phenotype were also ob-
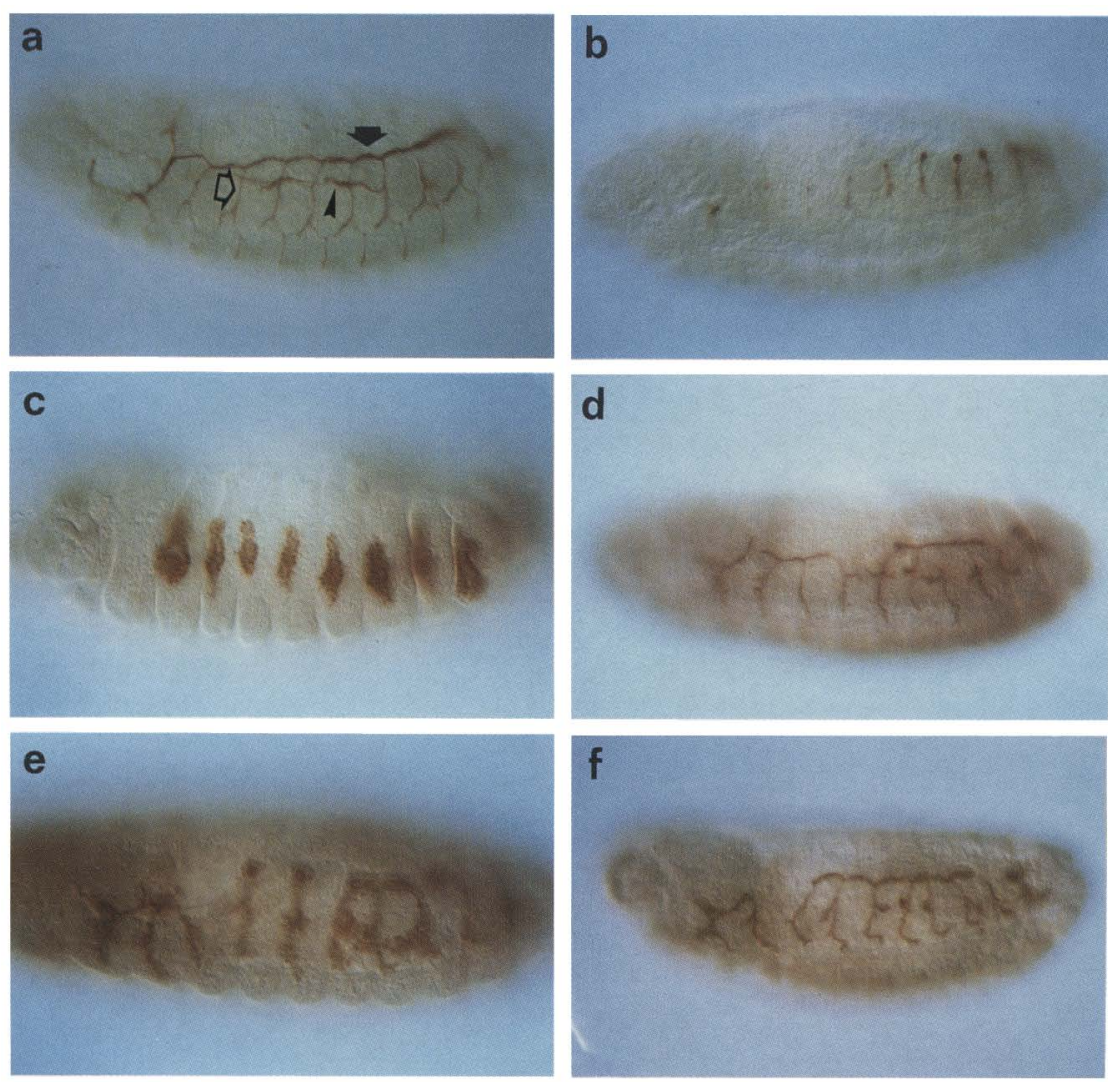

g
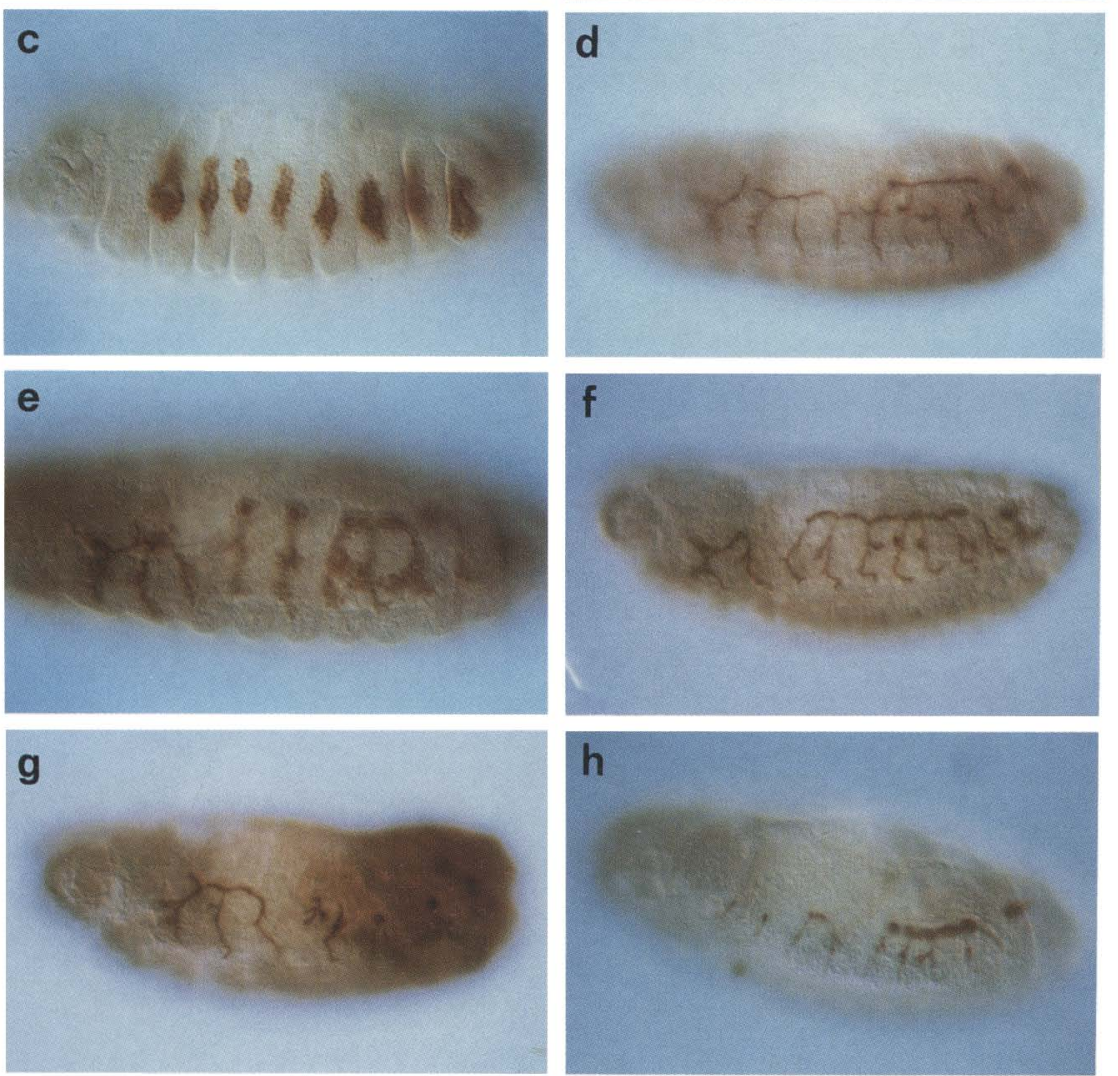

Figure 3. Rescue of tracheal migration defects of $b t l$ embryos by the torso-DFGFR1 construct. Embryos generated in the cross described above were heat shocked at 5 and $7 \mathrm{hr}$ of embryonic development. At 11.5 hr AEL (late stage 14), the embryos were stained with antibodies against the tracheal lumen $(55)$, and in some cases with anti- $\beta$-gal antibodies, as well. Shown in the figure is the tracheal phenotype of experimental embryos of the following genotypes: $(a)$ wild-type embryo stained with antibody 55 . Note that the normal development of the tracheal tree is not disrupted. The dorsal trunk is marked by a solid arrow, the visceral branches by an arrowhead, and the lateral branches by an open arrow. (b) Homozygous btl embryo stained with antibody 55. (c) Homozygous btl embryo stained with anti- $\beta$-gal antibodies. (d) Homozygous btl embryo containing the chimeric construct on the second chromosome, stained with antibody 55. Note the formation of an almost complete dorsal trunk, and migration of the tracheal cells to form visceral branches and lateral branches migrating toward the ventral ectoderm. $(e)$ Homozygous $b t l$ embryo containing the chimeric construct on the second chromosome, stained with antibody 55 and anti- $\beta$-gal antibodies. $(f)$ Homozygous btl embryo containing the chimeric construct on the third chromosome, stained with antibody 55. (g) An embryo with overlapping chromosomal deficiencies removing the $b t l$ locus, containing the chimeric construct on the second chromosome, stained with antibody 55 . (h) Homozygous btl embryo containing the chimeric construct on the second chromosome, heat shocked only once (at $5 \mathrm{hr}$ ), stained with antibody 55 . 
served upon activation of the torso-DFGF-R1 construct in flies bearing a chromosomal deficiency that deletes the btl locus; the dorsal trunk is fused in several segments, and considerable elongation of the lateral branches is seen (Fig. $3 \mathrm{~g}$ ). The less pronounced rescue in this case is presumably attributed to the absence of additional genes included in the deleted chromosomal region, leading to other morphological defects. The rescue of the tracheal phenotype of the deficiency strain excludes the possibility that in the experiments described above, residual activity from the mutant $b t l$ alleles plays a role in determining the directionality of tracheal migration.

Following ubiquitous expression of torso-DFGF-R1, tracheal migration in wild-type embryos remains unaffected, whereas migration of tracheal branches in btl mutants is rescued. We therefore conclude that DFGF$\mathrm{R} 1$ by itself does not provide tracheal cells with directive cues but rather, plays a critical permissive role in tracheal development.

\section{The effects of single heat shocks on tracheal migration}

Normally, DFGF-R1 is expressed throughout the course of tracheal morphogenesis (Glazer and Shilo 1991). It is not clear however, whether DFGF-R1 function is required only in the initial stages of the migration process or whether it is continuously required during outgrowth. This issue may be addressed by a single heat shock that would allow the presence of significant levels of the torso-DFGF-R1 protein for only a limited time period (2-3 hr according to Fig. 1), representing only a fraction of the entire interval encompassing the migration process. The extent of rescue following a single heat shock may be assessed, because the tracheal cells migrate over long distances while forming the stereotypic patterns, such that subtle changes in the extent of migration should be noticeable.

A similar experimental procedure to that described above was carried out, except that the embryos were heat shocked only at $5 \mathrm{hr}$ of embryonic development. As seen in Figure $3 \mathrm{~h}$, a single early heat shock led to a reduced correction of the mutant tracheal phenotype, as compared to the extent of migration induced by multiple heat shocks (Fig. 3d,e); the dorsal trunk was fused only at the posterior segments, the visceral branches did not form and ventral migration was more restricted. We can therefore infer from these results that activated DFGF$\mathrm{R} 1$ is likely to be required more than once, perhaps continuously during the process of tracheal migration.

A single heat shock was also carried out at $4 \mathrm{hr}$ of embryonic development, so that the torso-DFGF-R1 protein would be expressed before tracheal-cell fate determination and the onset of migration. The extent of rescue of migration observed in this case was less pronounced than that following a single heat shock at $5 \mathrm{hr}$; fusion of the tracheal cells forming the dorsal trunk in each segment with the cells of the adjacent segment was usually not observed (not shown). The lower extent of rescue may be accounted for by lower levels of the chimeric protein at the time when tracheal migration is initiated. In parallel, tracheal-cell fates were monitored to determine whether early and ubiquitous expression of the chimeric construct induced aberrant fates. We found that no additional cells expressing $\beta$-gal were detected in the presence of two different enhancer traps that mark cells of the tracheal lineage (H82 in the btl locus /Klämbt et al. 1992) and 1-eve-1 (Perrimon et al. 1991) (not shown). Likewise, following a double heat shock at 5 and $7 \mathrm{hr}$, no additional tracheal cells expressing the $\beta$-gal H82 marker were detected (Fig. 3e). The marked tracheal cells are positioned only along the migration routes and are found at the expected number. These results are in agreement with the finding that no detectable defects in general tracheal-cell fate are seen in btl null mutant embryos.

We have taken further advantage of the inducibility of the torso-DFGF-R 1 construct in $b t l$ mutant embryos to define the time window during which both the external guiding cues and the ability of the tracheal cells to respond to them persist. This was achieved by testing whether tracheal migration could be initiated later than the normal phase (at $6 \mathrm{hr}$ of embryonic development) by inducing expression of the chimeric receptor at $7.5,8$ or $9 \mathrm{hr}$ AEL. Induction at $7.5 \mathrm{hr}$ allowed the cells in the dorsal trunk of some segments to migrate anteriorly to the point where they are able to make contacts with the cells at the adjacent segment. Migration of the visceral and ventral branches is also observed (Fig. 4a). Induction at 8 or $9 \mathrm{hr}$ does not rescue migration of the dorsal trunk cells. However, some ventral and visceral migration can still be observed (Fig. 4b). These results demonstrate that the external cues, as well as the migration competence of the tracheal cells, are retained several hours beyond the normal onset of the migration process.
Figure 4. Defining the window of competence for the migration of tracheal cells. Embryos generated in the cross described above were heat shocked once, transferred to $18^{\circ} \mathrm{C}$ until $11.5 \mathrm{hr}$ (late stage 14) and stained with antibody 55 . (a) Heat shock at $7.5 \mathrm{hr}$. Note partial fusion of the dorsal trunk between segments (solid arrow) and the migration of visceral and lateral branches. (b) Heat shock at $9 \mathrm{hr}$. Lateral migration is still observed (open arrow).
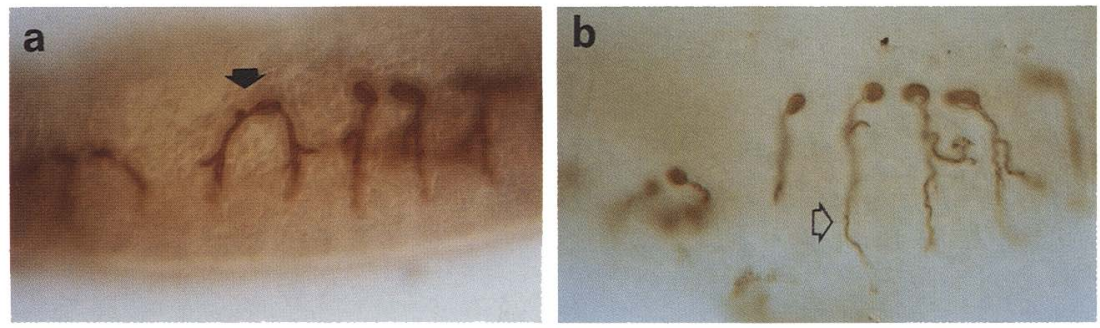
The intracellular pathway triggered by DFGF-R1 is shared by other RTKs

The embryonic expression and activity of DFGF-R1 is highly restricted to the tracheal and midline glial cells and is essential for biological processes that are distinct from those triggered by DER, torso or sevenless (Klämbt et al. 1992). To what extent is this distinct biological response based on unique intracellular signaling elements? The availability of a biological assay for DFGF$\mathrm{R} 1$ function, using the torso dominant chimeras in the context of tracheal migration, allows testing of the intracellular signaling specificities of the other RTKs, while ignoring the variability in their ligand recognition domains. Rescue of the $b t l$ phenotype by activation of other Drosophila RTKs in tracheal cells would indicate that a common signaling pathway is shared by those receptors.

Four additional torso constructs analogous to the torso-DFGF-R1 chimera were generated, in which the intracellular kinase domains are derived from other Drosophila RTKs including DFGF-R2 (M. Beiman, L. Glazer and B.-Z. Shilo, unpubl.; Shishido et al. 1993), referred to as DFR1, DER (Livneh et al. 1985), sevenless (Hafen et al. 1987), and torso itself (Sprenger et al. 1989). As the expression of all constructs is regulated by the same heat shock promoter, activation of the chimeric proteins in tracheal cells, in addition to all other embryonic cells, is expected. Following the generation of trans- formed lines, similar crosses and multiple heat shock protocols were used to test the ability of the different chimeras to correct the $b t l$ tracheal phenotype. It is striking that all constructs displayed the biological potential to rescue the $b t l$ migration defects (Fig. $5 \mathrm{a}-\mathrm{d}$ ). Because the extent of rescue may be influenced by the structure of the cytoplasmic domain, as well as by its expression level, the potency of each construct cannot be quantitatively assayed. Although one could expect general morphological defects resulting from the ubiquitous induction of activated RTKs, no such abnormalities were seen. This may indicate that the activation levels of the chimeric constructs are less effective than those achieved by triggering the corresponding RTK pathways with their endogenous ligands.

These results suggest that common components of an intracellular signaling pathway could be triggered in tracheal cells upon activation of the different Drosophila RTKs. If so, then other molecules in this pathway, activated downstream of the receptor, should elicit a similar biological effect following activation. An activated Drasl gene was introduced in a form of a cDNA containing an activating mutation at codon 13 that is expressed under the heat shock promoter and is integrated into the second chromosome (Lu et al. 1993). Indeed, induction of this construct in a btl background allowed partial rescue of the migration defects (Fig. 5e).

The Drosophila Draf protein is a serine/threonine cytoplasmic kinase that was shown to be activated in RTK
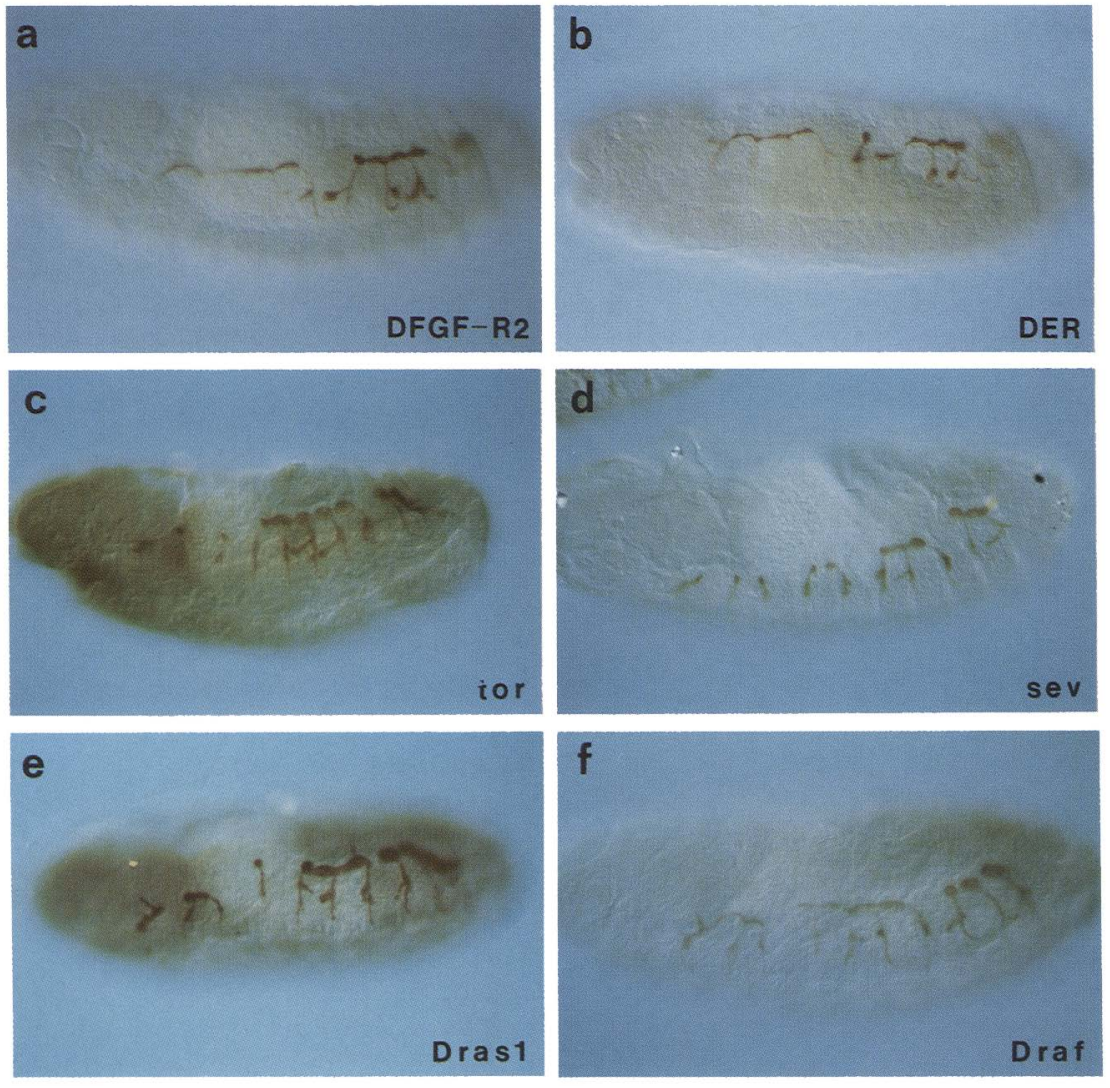

Figure 5. Rescue of $b t l$ tracheal migration defects by other activated Drosophila RTKs, and by activated Drasl and Draf. Double heat-shock protocols (at 5 and $7 \mathrm{hr}$ AEL) were employed to examine the tracheal phenotype of embryos homozygous for btl and heterozygous for activated constructs of other Drosophila RTKs or downstream elements in their pathway. Fixation and staining were carried out as above. Shown in the figure is the resultant tracheal phenotype of btl embryos carrying the following constructs: $|a|$ torso-DFGF-R2; $(b)$ torso-DER; (c) torso ${ }^{4021}$; (d) torso-sev; (e) activated Dras1; $(f)$ torso-Draf. 
pathways downstream to ras (Dickson et al. 1992b; Han et al. 1993; Lu et al. 1993). An activated Draf protein was generated previously by fusion of the kinase portion of Draf to the extracellular domain of the dominant torso allele, thus eliminating the inhibitory effects of the Draf amino-terminal sequences (Dickson et al. 1992b). Expression of the torso-Draf chimera also resulted in a partial rescue of the tracheal migration phenotype in $b t l$ mutant embryos (Fig. 5f). These results indicate that Drasl and Draf are downstream elements in the DFGFR1 signaling pathway.

\section{Discussion}

\section{The role of DFGF-R1 (breathless) in tracheal migration}

Analysis of the phenotypes of breathless mutant embryos has revealed a role for the DFGF-R 1 receptor that is distinct from the other RTKs characterized thus far in Drosophila. Receptors like torso, sevenless, and DER were shown to be essential for establishment of cell fates in different developmental contexts (for review, see Shilo 1992). For example, in the absence of torso function, the correct fate of the terminal structures is not established (Sprenger et al. 1989), and the lack of sevenless activity results in failure to determine the $\mathrm{R} 7$ photoreceptor cell fate (for review, see Rubin 1991). Absence of DER activity leads to loss of dorsal polarity in the follicle cells (Schüpbach 1987; Price et al. 1989) and loss of ventral cell fates in the embryonic ectoderm (Raz and Shilo 1993). In complementary experiments, dominant gainof-function alleles of torso or sevenless were shown to give rise to an excess of terminal structures or extra R7 cells, respectively (Klinger et al. 1988; Basler et al. 1991).

In contrast, DFGF-R1 does not seem to be involved in determination of cell fates; mutant $b$ tl embryos deficient for DFGF-R1 appear to express the proper markers and display the normal cell number in the two embryonic tissues in which the gene is expressed, that is, the tracheal system and midline glial cells of the CNS (Klämbt et al. 1992). In accordance with this observation, we have shown that ectopic expression of the gain-of-function torso dominant/DFGF-R1 protein did not give rise to extra tracheal cells. DFGF-R1 thus appears to play a role after the initial fates of the tracheal and midline cells have been determined, in facilitating their migration: In the absence of DFGF-R1 activity, the tracheal cells do not initiate normal migration and remain at the tracheal pits. Similarly, the posterior midline glial cells in each segment fail to reach the posterior commissure (Klämbt et al. 1992). This work has focused on the role of DFGF$\mathrm{R} 1$ in tracheal-cell migration because this system involves migration over large distances such that fine alterations can be scored.

To elucidate the role of DFGF-R1 in cell migration, two different hypotheses have been considered. One hypothesis assumes that the receptor dictates the directionality of migration by responding to a ligand that could be displayed in a pattern restricted to the migration tracts. In this way, localized activation of the receptor may determine the direction in which the cells mi- grate. The second hypothesis implicates DFGF-R1 function in other aspects of migration, such as cell motility or induction of expression of additional molecules essential for migration. It was possible to distinguish between these two alternatives by utilizing the torso-DFGF-R1 construct in which activation of the receptor is constitutive and independent of the ligand. Because the construct is under the $h s p 70$ promoter, the timing of expression could be manipulated.

We have shown that in wild-type embryos activation of the chimeric construct in all tracheal cells, at the time when tracheal migration normally occurs, did not give rise to defects in the migration pattern. This suggested that the endogenous receptor may not be activated in a spatially restricted manner in these cells. We then tested the ability of the activated receptor to rescue the migration defects of mutant $b t l$ embryos. Indeed, the expression of the chimeric receptor during the period of tracheal morphogenesis gave rise to a partial rescue of the migration defects. A continuous dorsal trunk was formed between most segments, and extensions toward the ventral ectoderm and mesoderm were observed. All of the migrating branches appeared to follow the stereotypic tracts, thus demonstrating that a deregulated receptor can mediate normal migration. The rescue was incomplete however; the dorsal branches were not formed and some discontinuities in the dorsal trunk were observed. This partial rescue could be attributed to an insufficient level or activity of the chimeric receptor. In support of this notion is the finding that a more pronounced rescue by the chimeric construct was obtained

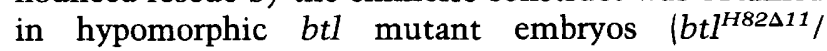
$\left.b t l^{H 82 \Delta 11}\right)$, as reflected by the formation of an almost fully fused dorsal trunk and some dorsal branches (not shown). Quantitative parameters are thought to be crucial for the biological activity of the endogenous DFGF$\mathrm{R} 1$, as well. The severity of the migration defects in $b t 1$ mutants appears to correlate with the level of DFGF-R1 expression. A reduced level of DFGF-R1 transcripts in the hypomorphic $b t 1^{5 H 82 \Delta 1} / b t 1^{H 82 \Delta 1}$ embryos leads to partial migration of the tracheal cells (Klämbt et al. 1992).

The normal migration process of the tracheal cells generating the major branches, spans a period of $6-7 \mathrm{hr}$ (from stage 11 to stage 15, 6-13 hr AEL) (Manning and Krasnow 1993). However, the level of the chimeric protein starts decaying within $2-3 \mathrm{hr}$ following induction. It was, therefore, possible to ask whether a single burst of DFGF-Rl activity is sufficient to restore normal migration, or whether the protein is required continuously, so that multiple inductions would give rise to a more pronounced rescue. We have shown that several heat shocks during the prominent stages of migration result in a significantly improved rescue relative to a single heat shock, suggesting that the DFGF-R1 protein is required continuously during migration.

Because our experiments have ruled out the hypothesis that DFGF-R1 determines the directionality of tracheal migration, alternative models for its role should be considered. One possibility is that DFGF-R1 triggers 
post-translational modifications of molecules that influence motility. Phosphorylation, for example, (either directly by the receptor or indirectly by downstream kinases in the pathway/ could alter the adhesive properties of the focal contacts or the attachment of actin to leading edges of migration. The involvement of RTKs and their downstream elements (e.g., the small GTP-binding proteins rac and rho) in actin organization has been previously described (Ridley et al. 1992; Ridley and Hall 1992). It has also been demonstrated that activation of the EGF receptor induces cell shape changes through MAP kinase phosphorylation of phospholipase $A_{2}$, leading to the production of arachidonic acid (Bliska et al. 1993; Peppelenbosch et al. 1993). RTKs could also be implicated in actin organization by way of PLC $\gamma$ activation that leads to release of prolifin from its association with $\mathrm{PIP}_{2}$; prolifin may then interact with actin monomeres and trigger their polymerization (for review, see Machesky and Pollard 1993).

An additional possibility is that activation of DFGFR1 leads to expression of genes whose products are required for the motility of the cells, or for their guided migration, for example, proteins regulating the actin assembly cycle or receptors for the signals guiding migration. Because DFGF-R1 appears to be required continuously, the induced proteins may be short-lived so that their initial synthesis may not suffice.

The cue(s) guiding the directional migration of the tracheal cells remain elusive. Our experiments suggest that they are not transient. As no migration of tracheal cells occurs in breathless embryos, we could ask how late in embryonic development the migration can be restored by the activated torso-DFGF-R1 construct. This window of migration competence defines the period during which the external migration cues persist, and the ability of tracheal cells to recognize them is retained. We have shown that this window is broad. Formation of the tracheal trunk could be observed following induction as late as $7.5 \mathrm{hr}$ AEL (i.e., about $2.5 \mathrm{hr}$ after the normal onset of migration, taking into account a $1-\mathrm{hr}$ period necessary for accumulation of the chimeric protein). Furthermore, extensions toward the ventral ectoderm were observed even after inducing the chimeric protein at $9 \mathrm{hr}$ AEL. These experiments indicate that the tracheal cells retain the competence to recognize external guiding cues for several hours and, at the same time, that these cues are stable and accessible.

\section{Control of migration by other RTKs}

In vertebrate systems, several RTKs were shown to be involved in processes of cell migration, most notably in the context of the formation of organized tubular structures. Basic FGF was shown to be a potent angiogenic factor capable of stimulating division and migration of endothelial cells during wound healing and vascularization of tumors (Folkman and Klagsbrun 1987). Proliferation of endothelial cells can also be promoted by vascular endothelial growth factor (VEGF), which is the ligand of the flt RTK (Keck et al. 1989; Leung et al. 1989; De Vries et al 1992). In addition, flt and its ligand have been implicated in vasculogenesis in normal tissues and during anoxia (Plate et al. 1992; Shweiki et al. 1992). Another RTK, flk-1, was shown to bind VEGF and to be an early marker for endothelial cell precursors (Millauer et al. 1993; Yamaguchi et al. 1993). Finally, activation of the met RTK by its ligand, the HGF/scatter factor protein, leads under some conditions to cell motility (for review, see Rosen et al. 1991) and under other circumstances, to the formation of tubular structures in culture (Tsarfaty et al. 1992). This receptor is normally expressed in the cells forming the breast ducts and in cells of the digestive tracts.

The apparent similarities between processes of vasculogenesis and angiogenesis and the formation of the tracheal system are interesting. The possibility that RTKs participating in these processes may play a similar role to that of DFGF-R1 should be considered.

\section{Universal RTK signaling pathways}

The ability of the torso-DFGF-R 1 chimera to rescue tracheal migration in breathless embryos provided a powerful biological system to test the potential of other Drosophila RTKs to rescue the same defect. Indeed, the dominant torso protein, as well as torso chimeras containing the cytoplasmic domains of DFGF-R2, DER, and sevenless were all able to rescue partially the migration of tracheal cells. The rescue was less pronounced than the one seen following induction of the torso-DFGF-R1 chimera, but formation of the dorsal trunk, as well as lateral extensions towards the ventral ectoderm, could be induced. This experiment indicates that in spite of the diversity in the structure of the cytoplasmic kinase domains (e.g., only $40 \%$ identity between DFGF-R1 and DER), their biological functions appear to be interchangeable, presumably because they trigger the same intracellular pathway.

The molecular basis for a common pathway triggered by different RTKs has been unraveled following an extensive dissection of the signaling pathways carried out in vertebrate systems, Drosophila, and C. elegans. Following receptor activation and dimerization, transphosphorylation generates phosphotyrosine residues on the receptor, which are recognized by an adapter protein (termed Grb2, Drk, or sem5) containing one SH2 and two SH3 domains (Clark et al. 1992; Lowenstein et al. 1992; Olivier et al. 1993; Simon et al. 1993). The RTK may associate directly with Grb2/Drk, or alternatively associate with the SH2 domain of another adapter protein (e.g., IRS and Shc), that can interact with Grb2/Drk following its phosphorylation on tyrosine (Skolnik et al. 1993). Through the SH3 domains Grb2/Drk is complexed in the cytoplasm with the Sos protein, which facilitates GDP/GTP exchange on ras (Buday and Downward 1993; Egan et al. 1993; Gale et al. 1993; Li et al. 1993; Rozakis-Adcock et al. 1993). Triggering of the receptor thus brings Sos to the membrane by virtue of the binding of the adapter molecule. Activation of Sos leads to activation of ras, followed by triggering of raf, MAP kinase kinase and finally MAP kinase, which may be 
translocated into the nucleus and phosphorylate transcription factors (Moodie et al. 1993; Warne et al. 1993; Zhang et al. 1993; for review, see Leevers and Marshall 1992). Thus, the promiscuity of the SH2 domain of Grb2/Drk/Sem5 that can bind (directly or indirectly) different activated RTKs, may explain the ability of several RTKs to trigger the same cytoplasmic pathway (Songyang et al. 1993).

Because different RTKs were able to rescue the breathless phenotype, the implication was that they were all triggering a similar pathway in the tracheal cells. The prediction was that activation of cytoplasmic components of the pathway would give rise to a similar result. Indeed, an activated Drasl construct was able to partially rescue the $b t l$ tracheal migration defects. Dras 1 was identified previously as an essential component in the signaling pathways of sevenless and DER (Simon et al. 1991). In C. elegans ras was shown to be downstream to let-23, an EGF receptor homolog (for review, see Sternberg and Horvitz 1991). In addition, activated Dras1 could rescue the torso or sevenless phenotypes (Fortini et al. 1992; Lu et al. 1993).

Draf was shown to be a component that is active downstream to ras in the sevenless and torso pathways (Dickson et al. 1992b; Lu et al. 1993), and its deregulation gave rise to a sevenless gain-of-function phenotype (Dickson et al. 1992b). The unrescued maternal effect phenotype of Draf mutants suggests that Draf also participates in the DER pathway (Melnick et al. 1993). When the activated torso-Draf construct was used to rescue the breathless defect, partial rescue of migration was indeed observed. This result indicates that Draf is a crucial component in a signaling pathway of an FGF receptor homolog. Notably, it was recently shown in $\mathrm{Xe}$ nopus that raf is a downstream element in the pathway of the FGF receptor triggering mesoderm induction (MacNicol et al. 1993).

The apparent universal signaling pathways of RTKs raises the question concerning the basis for the unique biological function of each receptor. A major tenet of this specificity seems to be the cell type in which the receptor is activated, which may present a characteristic spectrum of transcription factors and other proteins that could be either activated or inactivated by the MAP kinase. An additional mechanism that may provide the biological specificity is the differential association of a given $\mathrm{RTK}$ with various $\mathrm{SH} 2$ containing proteins, for example, GAP, PLC $\gamma$ and PI kinase (for review, see Cantley et al. 1991). Hence, parallel pathways triggered in the cell by each RTK could also contribute to its corresponding function. The existence of parallel pathways triggered directly by the receptor may account for the more pronounced rescue obtained with torso-DFGF-R1 as compared to the other torso chimeras, and the Drasl or Draf constructs.

\section{Materials and methods}

\section{Constructs}

The torso-DFGF-R1, torso-DFGF-R2 and torso-DER fusion constructs were generated by introducing EcoRI sites via in vitro mutagenesis into the sequences encoding the immediate juxtamembrane regions of the tyrosine kinase domain of each gene. Each of these kinase domains was then inserted in place of the sevenless kinase in the sE-torso ${ }^{4021}$-sev construct described by Dickson et al. (1992a). The predicted amino acid sequences at the fusion site of each chimeric receptor are as follows: $\mathrm{C}_{420} \mathrm{RIR}_{626}, \mathrm{C}_{420} \mathrm{RIR}_{319}$, and $\mathrm{C}_{420} \mathrm{RIR}_{844}$ where $\mathrm{C}_{420}$ is the predicted final residue in the torso transmembrane domain, $R I$ is a novel sequence encoded by the EcoRI linker and $R_{365}, R_{319}$, and $R_{844}$ are the predicted immediate juxtamembrane residues of DFGF-R1, DFGF-R2 and DER type 2, respectively. These cDNA constructs, as well as the torso-sev (Dickson et al. 1992a), torso-raf (Dickson et al. 1992b), and the full-length torso 4021 cDNA (a derivative of the pB4021, Sprenger and Nüsslein-Volhard 1992) were then cloned into a pW8 derivative transformation vector in which they are expressed under the control of the $h s p 70$ promoter and a single copy of the $1.2-\mathrm{kb} s e v$ enhancer (Basler et al. 1989). Transgenic flies were generated by P-element-mediated germline transformation according to the standard protocols (Spradling 1986). The activated Drasl construct was described previously by Lu et al. (1993).

\section{Fly strains}

As breathless null alleles we used the $w ; b t l^{H 82 \Delta 3} / T M 3$ elavlacZ strain that was generated by an imprecise excision of a $\mathrm{P}$ element upstream to the $b t l$ locus that retained $\beta$-gal expression, and the ru cu ca btI $I^{L G 19} / T M 3$ elav-lacZ strain carrying an EMS-induced $b t l$ allele (Klämbt et al. 1992). The hypomorphic $w$; $b t^{H 82 \Delta 11} / T M 3$ elav-lacZ strain was also used. To generate embryos with the $b t l$ deficiency background, the overlapping deficiency chromosomes $\mathrm{fz} \mathrm{GF}^{3 \mathrm{~b}}$ and $\mathrm{f} z \mathrm{GS}^{1 \mathrm{a}}$ were used.

The chimeric torso constructs were derived from the following strains: (1) ST4021R1.1 (w sev; P[sE-torso ${ }^{4021}$-DFGF-R1)/ $\mathrm{CyO}$ ) carries the torso-DFGF-R1 construct on the second chromosome; (2) ST4021R1.2 (w sev; P[sE-torso ${ }^{4021}$-DFGF-Rl] $b t l^{L G 19} / T M 3$ elav-lacZ) carries the torso-DFGF-R1 construct on the third chromosome recombined to a null btl allele; (3) ST4021R2 ( $w$ sev; P[sE-torso ${ }^{4021}$-DFGF-R2]/ + ) carries the torso-DFGF-R2 construct on the second chromosome; (4) ST4021D ( $w$ sev; P[sE-torso ${ }^{4021}$-DER]) carries the torso-DER construct on the X chromosome; (5) ST4021S.4 (w sev; P[sEtorso ${ }^{4021}$-sev]) carries the torso-sev construct on the second chromosome (Dickson et al. 1992a); (6) ST4021 (w sev; P[sEtorso ${ }^{4021}$ ]) carries the torso dominant construct on the $\mathrm{X}$ chromosome; and (7) SRT4021 (w sev; P[sE-torso ${ }^{4021}$-raf]/CyO) carries the torso-raf construct on the second chromosome (Dickson et al. 1992b). The fly strain that carries the activated Dras 1 construct under the heat-shock promoter (P[hs-9.4-M8]/CyO) was described by Lu et al. (1993).

\section{Heat-shock protocols}

For the heat-shock procedures, egg lay plates of staged embryos were incubated at $37^{\circ} \mathrm{C}$ for $20 \mathrm{~min}$ and returned to $18^{\circ} \mathrm{C}$ for the required time period. The embryos were stained at late stage 14 , when their age was equivalent to $11.5 \mathrm{hr}$ at $25^{\circ} \mathrm{C}$. For each experiment, at least 100 staged embryos were scored for tracheal phenotypes. Rescued btl embryos were observed at the expected frequency: $\sim 12.5 \%$ for the crosses with the torsoDFGF-Rl construct on the second chromosome or $\sim 25 \%$ for the strain with torso-DFGF-R1 recombined to $b t l$ on the third chromosome (ST4021R1.2).

\section{Antibodies, blotting, and staining procedures}

Antibody 55 stains the lumen of the tracheal tubes. It was gen- 
erated fortuitously in guinea pigs and is similar to antibody 84 described previously (Klämbt et al. 1992). Rabbit anti- $\beta$-gal antibodies were purchased from Cappel. Anti-DFGF-R1 antibodies were generated in guinea pigs against the cytoplasmic domain of DFGF-R1 (Glazer and Shilo 1991).

For Western blot analysis, lysates were prepared from counted heat-shocked embryos $(\geqslant 100)$, collected following heat shock and incubation for specific time periods at $18^{\circ} \mathrm{C}$. Embryos were homogenized in RIPA lysis buffer at a density of 1 embryo/ $\mu$ l of lysis buffer [0.05 M Tris- $\mathrm{HCl}(\mathrm{pH} 8.0), 0.15 \mathrm{M} \mathrm{NaCl}, 1 \%$ Triton $\mathrm{X}-100,0.5 \%$ deoxycholate and $0.1 \%$ SDS supplied with protease inhibitors $10 \mu \mathrm{g} / \mathrm{ml}$ aprotinin and $100 \mu \mathrm{g} / \mathrm{ml}$ PMSF). Lysates were electrophoresed through $7.5 \%$ polyacrylamide gels that were then electroblotted onto nitrocellulose filters. The torsoDFGF-R1 chimeric protein was visualized with polyclonal antibodies specific for the cytoplasmic domain of DFGF-R1 (Glazer and Shilo 1991) followed by the enhanced chemiluminescence (ECL) immunodetection procedure (Amersham).

Standard whole-mount antibody staining procedures of embryos were used (Ashburner 1989).

\section{Acknowledgments}

We thank N. Perrimon for providing the hs-Dras 1 line, and Erez Raz, Talila Volk, and Mark Krasnow for critical reading of the manuscript. The work was supported by grants from the $\mathrm{Na}$ tional Institutes of Health and the US-Israel Binational Science Foundation (B.S.).

The publication costs of this article were defrayed in part by payment of page charges. This article must therefore be hereby marked "advertisement" in accordance with 18 USC section 1734 solely to indicate this fact.

\section{References}

Ashburner, M. 1989. Drosophila: A laboratory manual. Cold Spring Harbor Laboratory Press, Cold Spring Harbor, New York.

Basler, K., P. Siegrist, and E. Hafen. 1989. The spatial and temporal expression pattern of sevenless is exclusivly controlled by gene-internal elements. EMBO J. 8: 2381-2386.

Basler, K., B. Christen, and E. Hafen. 1991. Ligand-independent activation of the sevenless receptor tyrosine kinase changes the fate of cells in the developing Drosophila eye. Cell 64: 1069-1081.

Bier, E., H. Vassin, S. Shepard, K. Lee, K. McCall, S. Barbel, L. Ackerman, R. Carretto, T. Uemura, E. Grell, L.Y. Jan, and Y.N. Jan. 1989. Searching for pattern and mutation in the Drosophila genome with a p-lacZ vector. Genes \& Dev. 9: 1273-1287.

Bliska, J.B., J.E. Galán, and S. Falkow. 1993. Signal transduction in the mammalian cell during bacterial attachment and entry. Cell 73: 903-920.

Buday, L. and J. Downward. 1993. Epidermal growth factor regulates $\mathrm{p} 21^{\text {ras }}$ through the formation of a complex of receptor, Grb2 adaptor protein, and Sos nucleotide exchange factor. Cell 73: 611-620.

Cantley, L.C., K.R. Auger, C. Carpenter, B. Ducksworth, A. Graziani, R. Kapeller, and S. Soltoff. 1991. Oncogenes and signal transduction. Cell 64: 281-302.

Clark, S.G., M.J. Stern, and H.R. Horovitz. 1992. C. elegans cell-signalling gene sem-5 encodes a protein with $\mathrm{SH} 2$ and
SH3 domains. Nature 356: 340-344.

DeVries, C., J.A. Escobedo, H. Ueno, K. Houck, N. Ferrara, and L.T. Williams. 1992. The fms-like tyrosine kinase, a receptor for vascular endothelial growth factor. Science 255: 989991.

Dickson, B., F. Sprenger, and E. Hafen. 1992a. Prepattern in developing Drosophila eye revealed by an activated torsosevenless chimeric receptor. Genes \& Dev. 6: 2327-2339.

Dickson, B., F. Sprenger, D. Morrison, and E. Hafen. 1992b. raf functions downstream of ras 1 in sevenless signal transduction pathway. Nature 360: 600-604.

Egan, S.E., B.W. Giddings, M.W. Brooks, L. Buday, A.M. Sizeland, and R.A. Weinberg. 1993. Association of Sos Ras exchange protein with Grb2 is implicated in tyrosine kinase signal transduction and transformation. Nature 363: 45-51.

Folkman, J. and M. Klagsbrun. 1987. Angiogenic factors. Sci ence 235: 442-447.

Fortini, M.E., M.A. Simon, and G.M. Rubin. 1992. Signalling by the sevenless protein tyrosine kinase is mediated by Ras 1 activation. Nature 355: 559-561.

Gale, N.W., S. Kaplan, E.J. Lowenstein, J. Schlessinger, and D. Bar-Sagi. 1993. Grb2 mediates the EGF-dependent activation of guanine nucleotide exchange on Ras. Nature 363: 88-92.

Glazer, L. and B.-Z. Shilo. 1991. The Drosophila FGF-R homolog is expressed in the embryonic tracheal system and appears to be required for directed tracheal cell extension. Genes \& Dev. 5: 697-705.

Goodman, C.S. and C.J. Shatz. 1993. Developmental mechanisms that generate precise patterns of neuronal connectivity. Cell 72: 77-98.

Hafen, E., K. Basler, J.E. Edstrom, and G.M. Rubin. 1987. sevenless, a cell-specific homeotic gene of Drosophila, encodes a putative transmembrane receptor with a tyrosine kinase domain. Science 236: 55-63.

Hamelin, M., Y. Zhou, M.-W. Su, I.M. Scott, and J.G. Culotti. 1993. Expression of the UNC-5 guidance receptor in the touch neurons of $\mathrm{C}$. elegans steers their axons dorsally. $\mathrm{Na}$ ture 364: 327-330.

Han, M., A. Golden, Y. Han, and P.W. Sternberg. 1993. C. elegans lin-45 raf gene participates in let- 60 ras-stimulated vulval differentiation. Nature 363: 133-140.

Hartenstein, V. and Y.N. Jan. 1992. Studying Drosophila embryogenesis with p-lacZ enhancer trap lines. Roux's Arch. Dev. Biol. 201: 194-220.

Ishii, N., W.G. Wadsworth, B.D. Stern, J.G. Culotti, and E.M. Hedgecock. 1992. Unc-6, a laminin-related protein, guides cell and pioneer axon migrations in C. elegans. Neuron 9: 873-881.

Keck, P.J., S.D. Hauser, G. Krivi, K. Sanzo, T. Warren, J. Feder, and D.T. Connolly. 1989. Vascular permiability factor, an endothelial cell mitogen related to PDGF. Science 246: 1309-1312.

Klämbt, C., L. Glazer, and B.-Z. Shilo. 1992. breathless, a Drosophila FGF receptor homolog, is essential for migration of tracheal and specific midline glial cells. Genes \& Dev. 6: 1668-1678.

Klinger, M., M. Erdélyi, J. Szabad, and C. Nüsslein-Volhard. 1988. Function of torso in determining the terminal anlagen of the Drosophila embryo. Nature 335: 275-277.

Leevers, S.J. and C.J. Marshall. 1992. MAP kinase regulation the oncogene connection. Trends Cell Biol. 2: 283-286.

Leung, D.W., G. Cachianes, W.-J. Kuang, D.V. Goddel, and N. Ferrara. 1989. Vascular endothelial growth factor is a secreted angiogenic mitogen. Science 246: 1306-1309.

Leung-Hagensteijn, C., A.M. Spence, B.D. Stern, Y. Zhou, M.W. Su, E.M. Hedgecock, and J.G. Culotti. 1992. Unc-5, a trans- 
membrane protein with immunoglobulin and thrombospondin type 1 domains, guides cell and pioneer axon migrations in C. elegans. Cell 71: 289-299.

Li, N., A. Batzer, R. Daly, V. Yajnik, E.Y. Skolnik, P Chardin, D. Bar-Sagi, B. Margolis, and J. Schlessinger. 1993. Guaninenucleotide-releasing factor hSOS1 binds to Grb2 and links receptor tyrosine kinases to Ras signaling. Nature 363: 8588.

Livneh, E., L. Glazer, D. Segal, J. Schlessinger, and B.-Z. Shilo. 1985. The Drosophila EGF receptor gene homolog: Conservation of both hormone binding and kinase domains. Cell 40: $599-607$.

Lowenstein, E.J., R.J. Daly, A.B. Batzer, W. Li, B. Margolis, R. Lammers, A. Ullrich, E.Y. Skolnik, D. Bar-Sagi, and J. Schlessinger. 1992. The SH2 and SH3 domain-containing protein Grb2 links receptor tyrosine kinases to ras signaling. Cell 70: 431-442.

Lu, X., T.-B. Chou, N.G. Williams, T. Roberts, and N. Perrimon. 1993. Control of cell fate determination by $\mathrm{p} 21^{\text {ras }} /$ Ras 1 , an essential component of torso signaling in Drosophila. Genes \& Dev. 7: 621-632.

Machesky, L.M. and T.D. Pollard. 1993. Profilin as a potential mediator of membrane-cytoskeleton communication. Trends Cell Biol. 3: 381-385.

MacNicol, A.M., A.J. Muslin, and L.T. Williams. 1993. Raf-1 kinase is essential for early Xenopus development and mediates the induction of mesoderm by FGF. Cell 73: 571-583.

Manning, G. and M.A. Krasnow. 1993. Development of the Drosophila tracheal system. In The development of Drosophila (ed. A. Martinez-Arias and M. Bate), Cold Spring Harbor Laboratory Press, Cold Spring Harbor, New York. In press.

Melnick, M.B., L.A. Perkins, M. Lee, L. Ambrosio, and N. Perrimon. 1993. Development and molecular characterization of mutations in the Drosophila-raf serine/threonine protein kinase. Development 118: 127-138.

Millauer, B., S. Wizigmann-Voss, H. Schnürch, R. Martinez, N.P.H. Møller, W. Risau, and A. Ullrich. 1993. High affinity VEGF binding and developmental expression suggest Flk-1 as a major regulator of vasculogenesis and angiogenesis. Cell 72: $835-846$

Moodie, S.A., B.M. Wilumsen, M.J. Weber, and A. Wolfman. 1993. Complexes of ras-GTP with raf-1 and mitogen-activated protein kinase kinase. Science 260: 1658-1661.

Olivier, J.P., T. Raabe, M. Henkemeyer, B. Dickson, G. Mbamalu, B. Margulis, J. Schlessinger, E. Hafen, and T. Pawson. 1993. A Drosophila SH2-SH3 adaptor protein implicated in coupling the sevenless tyrosine kinase to an activator of ras guanine nucleotide exchange, Sos. Cell 73:179-191.

Peppelenbosch, M.P., L.G.J. Tertoolen, W.J. Hage, and S.W. de Laat. 1993. Epidermal growth factor-induced actin remodeling is regulated by 5-lipoxygenase and cyclooxygenase products. Cell 74: 565-575.

Perrimon, N., E. Noll, K. McCall, and A. Brand. 1991. Generating lineage-specific markers to study Drosophila development. Developmental Genetics 12: 238-252.

Plate, K.H., G. Breier, H.A. Weich, and W. Risau. 1992. Vascular endothelial growth factor is a potential tumour angiogenesis factor in human gliomas in vivo. Nature 359: 845-848.

Price, J.V., R.J. Clifford, and T. Schüpbach. 1987. The maternal ventralizing locus torpedo is allelic to faint little ball, an embryonic lethal, and encodes the Drosophila EGF receptor homolog. Cell 56: 1085-1092.

Raz, E. and B.-Z. Shilo. 1993. Establishment of ventral cell fates in the Drosophila embryonic ectoderm requires the EGF receptor homolog (DER). Genes \& Dev. 7: 1937-1948.
Ridley, A.J. and A. Hall. 1992. The small GTP binding protein rho regulates the assembly of focal adhesions and actin stress fibers in response to growth factors. Cell 70: 389-399.

Ridley, A.J., H.F. Paterson, C.L. Johnston, D. Diekmann, and A. Hall. 1992. The small GTP-binding protein rac regulates growth factor-induced membrane ruffling. Cell 70: 401-410.

Rosen, E.M., J. Knesel, and I.D. Goldberg. 1991. Scatter factor and its relationship to hepatocyte growth factor and met. Cell Growth Diff. 2: 603-607.

Rozakis-Adcock, M., R. Fernley, J. Wade, T. Pawson, and D. Bowtell. 1993. The SH2 and SH3 domains of mammalian Grb2 couple the EGF receptor to Ras activator mSosl. $\mathrm{Na}$ ture 363: 83-85.

Rubin, G.M. 1991. Signal transduction and the fate of the R7 photoreceptor in Drosophila. Trends Genet. 7: 372-377.

Schüpbach, T. 1987. Germ line and soma cooperate during oogenesis to establish dorsoventral pattern of egg shell and embryo in Drosophila melanogaster. Cell 49: 699-707.

Shilo, B.-Z. 1992. Roles of receptor tyrosine kinases in Drosophila development. FASEB J. 6: 2915-2922.

Shishido, E., S.-I. Higashijima, Y. Emori, and K. Saigo. 1993. Two FGF-receptor homologues of Drosophila: One is expressed in mesodermal premordium in early embryos. $D e$ velopment 117: 751-761.

Shweiki, D., A. Itin, D. Soffer, and E. Keshet. 1992. Vascular endothelial growth factor induced by hypoxia may mediate hypoxia-initiated angiogenesis. Nature 359: 843-845.

Simon, M.A., G.S. Dodson, and G.M. Rubin. 1993. An SH3-SH2$\mathrm{SH} 3$ protein is required for $\mathrm{p} 21^{\text {Ras } 1}$ activation and binds to sevenless and Sos proteins in vitro. Cell 73: 169-177.

Simon, M.A., D.D.L. Bowtell, G.S. Dodson, T.R. Laverty, and G.M. Rubin. 1991. Rasl and a putative guanine nucleotide exchange factor perform crucial steps in signaling by the sevenless protein tyrosine kinase. Cell 67: 701-716.

Skolnik, E.Y., C.-H. Lee, A. Batzer, L.M., Vicentini, M. Zhou, R. Daly, M.J. Myers Jr, J.M. Backer, A. Ullrich, M.F. White, and J. Schlessinger. 1993. The SH2/SH3 domain-containing protein GRB2 interacts with tyrosine-phosphorylated IRS1 and Shc: implications for insulin control of ras signalling. $E M B O$ J. 12: 1929-1936.

Songyang, Z., S.E. Shoelson, M. Chaudhuri, G. Gish, T. Pawson, W.G. Haser, F. King, T. Roberts, S. Ratnofsky, R.J. Lechleider, B.G. Neel, R.B. Birge, J.E. Fajardo, M.M. Chou, H. Hanafusa, B. Schaffhausen, and L.C. Cantley. 1993. SH2 domains recognize specific phosphopeptide sequences. Cell 72: 767-778.

Spradling, A.C. 1986. P element mediated transformation. In Drosophila: A practical approach (ed. D.B. Roberts), pp. 175197. Oxford University Press, Oxford.

Sprenger, F. and C. Nüsslein-Volhard. 1992. Torso receptor activity is regulated by a diffusible ligand produced at the extracellular terminal regions of the Drosophila egg. Cell 71: 987-1001.

Sprenger, F., L.M. Setevens, and C. Nüsslein-Volhard. 1989. The Drosophila gene torso encodes a putative receptor tyrosine kinase. Nature 338: 478-483.

Sternberg, P.W. and H.R. Horvitz. 1991. Signal transduction during C. elegans vulval induction. Trends Genet. 7: 366371.

Szabad, J., M. Erdélyi, G. Hoffmann, J. Szidonya, and T. Wright. 1989. Isolation and characterization of dominant female sterile mutations of Drosophila melanogaster. II. Mutations on the second chromosome. Genetics 122: 823-835.

Tsarfaty, I., J.H. Resau, S. Rulong, I. Keydar, D.L. Faletto, and G.F. Vande Woude. 1992. The met proto-oncogene receptor and lumen formation. Science 257: 1258-1261. 
Warne, P.H., P.R. Viciana, and J. Downward. 1993. Direct interaction of Ras and the amino-terminal region of Raf- 1 in vitro. Nature 364: 252-355.

Yamaguchi, T.P., D.J. Dumont, R.A. Conlon, M.L. Breitman, and J. Rossant. 1993. flk-1, an flt-related receptor tyrosine kinase is an early marker for endothelial cell precursors. $D e$ velopment 118: 489-498.

Zhang, X.-F., J. Settelman, J.M. Kyriakis, E. Takeuchi-Suzuki, S.J. Elledge, M.S. Marshall, J.T. Bruder, U.R. Rapp, and J. Avruch. 1993. Normal and oncogenic $\mathrm{p} 21^{\text {ras }}$ proteins bind to the amino-terminal regulatory domain of c-Raf-1. Nature 364: 308-313. 


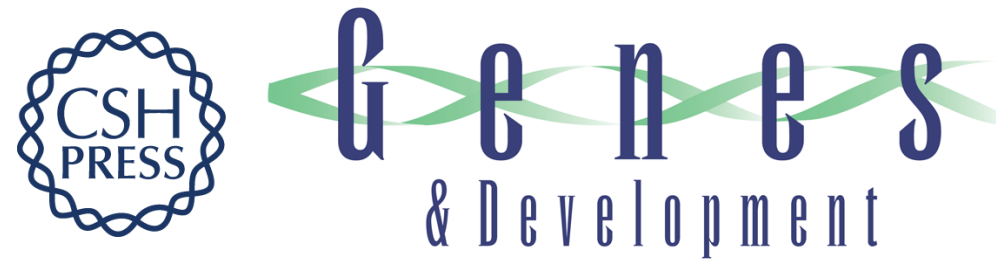

\section{Elucidation of the role of breathless, a Drosophila FGF receptor homolog, in tracheal cell migration.}

M Reichman-Fried, B Dickson, E Hafen, et al.

Genes Dev. 1994, 8:

Access the most recent version at doi:10.1101/gad.8.4.428

References This article cites 63 articles, 16 of which can be accessed free at:

http://genesdev.cshlp.org/content/8/4/428.full.html\#ref-list-1

License

Email Alerting

Service

Receive free email alerts when new articles cite this article - sign up in the box at the top right corner of the article or click here.

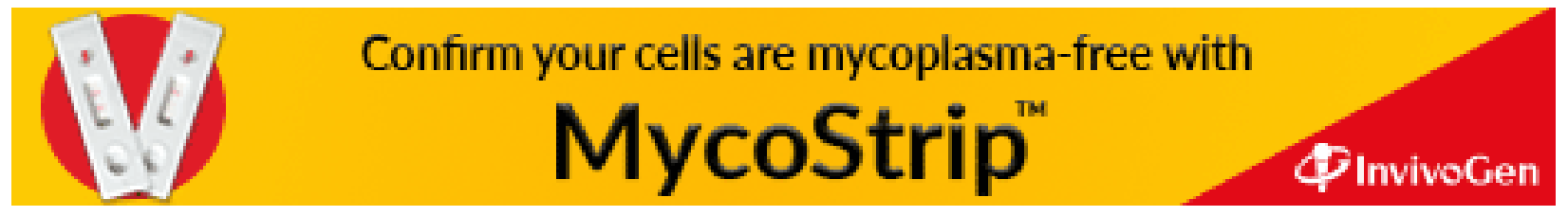

